\title{
Research on Solutions of Vocational School Students to Employment Pressure under the Perspective of Psychological Elasticity
}

\author{
Yichen Pan \\ Chongqing Industry \& Trade Polytechnic \\ Chongqing, 408000
}

\author{
Wei Wang \\ Faculty of Teacher Education \\ Yangtze Normal University \\ Chongqing 408000 \\ * Corresponding author
}

\begin{abstract}
Through a questionnaire survey of 430 vocational college students on treatment methods to employment pressure and their psychological elasticity, it is found that the correlation between employment pressure treatment methods and psychological elasticity of vocational college students reaches a significant level. The protective factors affect the individual's psychological elasticity by internal protection. With the increasing of psychological elasticity, the employment pressure response will be more positive. By improving the mental elasticity of vocational students, their ways of responding to employment pressure can become more positive.
\end{abstract}

Keywords-vocational students; solution to employment pressure; psychological elasticity; countermeasures

\section{INTRODUCTION}

The currently not optimistic employment condition has become a worry for contemporary college students. Employment pressure is increasing day by day. The coping styles of college students present different characteristics with the influence of various factors. In the face of the employment pressure, different vocational college students have different coping styles. However, what exactly influences their coping styles and how to effectively guide students to relieve their pressure are worth exploring. From the existing literature, it is found that although there are many discussions about college students' employment problems, there are not many researches on vocational college students, and there are fewer researches on the relationship between psychological elasticity and employment pressure coping style of vocational students.

Employment pressure[1] is defined as "When facing employment dilemma, individuals will produce a series of temporarily experiences: Physiologically manifested as thymus contractions, adrenal dilatation, etc., mentally manifested as tension, worry, anxiety, fear, etc."[2]. The word "response" was first used by Lazarus et al. Based on Freud's theories of defense mechanisms and stress, "response" was introduced to the field of psychological stress and was studied combining clinical psychology.[3] Therefore, the stress coping style can be simply summarized as the means by which individuals must comply with the requirements of environmental development and exclude the obsession of corresponding emotion. Many studies have shown that in the face of stressful situations, most students can take the initiative to make plans while staying calm, restrain themselves when necessary, reduce interference, and achieve goals. At the coping style of solving problems, students will learn from practice, deal with the difficulties rationally and try to find a solution to the problem. The least used means by college students are self-defeating, blaming others and drinking. This shows that college students can actively use a positive way to face the difficulties encountered. Because college students possess knowledge and ability to correctly recognize things, they tend to adopt positive solutions to problems when faced with difficulties. However, when positive strategies cannot be effective, they will also take measures such as avoidance. In sum, the coping style of college students is more mature in general.

With the rise of positive psychology and active education, whether active education can improve the employment stress response of vocational college students seems very valuable. Specifically, active education is based on the students' inherent positive abilities and qualities. It focuses on developing students' optimistic personalities, cultivates students' positive qualities at the individual and collective level so as to form positive personality traits. Psychoelasticity is one of the concepts in positive psychology. It is like a spring with contraction. When the spring is subjected to external forces, it will deform and respond to them. When the individual is in stress, his psychology will be affected, and the extent of impact is determined by the stress itself and the psychological endurance of the individual[5]. The domestic scholars $\mathrm{Yu}$ Xiaonan and Zhang Jianxin[6] proposed that the psychological elasticity consists of two important parts: one is the restored psychological state after the individual is stimulated, and the other is the individual's rebirth and growth after experiencing setbacks. Through the literature search on key words as "college students", "stress coping styles" and "psychological elasticity", it is found that there are relatively few studies on college students in this field. The objects studied in the existing literature are 
military college students. Their particularity determines that they are more likely to experience setbacks and difficulties in daily life and training than ordinary college students. According to Sun Jihong [7], Wan Yuchen [8], etc. who have studied military college students, the psychological elasticity of different gender students are different. The overall score of female students in statistics is lower than that of male students on average. This shows that the adjustment and adaptability of male students in military academies are better than that of female students when they are in trouble, and the family cohesion and individual ability of male students are relatively more prominent than that of female students. In addition, other studies also found that the psychological elasticity of military college students is generally better. In terms of education level, the mental elasticity of undergraduate military college students is significantly stronger than that of specialty college students; the mental elasticity of students in different regions is not significantly different. Researchers further explored the relationship between the psychological elasticity of military college students and their coping styles, and found that the better the psychological elasticity of military college student is, the more possibly they can find a solution to the difficulties encountered. That will enable them to live, study and train with a healthier and tougher mind, meet the challenges in society confidently and have a better growth. Therefore, it can be predicted that the psychological elasticity as an intrinsic factor will inevitably affect the college students' employment pressure treatment methods.

\section{RESEARCH METHODS}

\section{A. Research Object}

The participants in this study mainly came from Chongqing Industry \& Trade Polytechnic. We randomly selected students from grade one to grade three as the survey objects. We have distributed 500 questionnaires and collected 480 questionnaires, of which 430 were valid. The effective recovery rate is $89.6 \%$.

\section{B. Research Tools}

The "employment stress coping style questionnaire" uses the coping style questionnaire of college students' employment stress prepared by Luo Xili [9] of Southwest University.The questionnaire consists of 9 factors, a total of 39 questions, 9 factors are positive understanding, selfadvancement, seeking help, collecting employment information, compromise, adjusting the mentality, seeking support, diverting attention, venting and avoidance.The alpha coefficient of the questionnaire was 0.88 , and the questionnaire had good content and construct validity.Questionnaire responses were based on a five-point self-evaluation scoring method that was "completely inconsistent", "substantially inconsistent", "inconclusive", "substantially consistent", and "fully consistent".If you choose A you will get 1 point, 2 points for B,3 points for C, 4 points for $\mathrm{D}$, and 5 points for $\mathrm{E}$.

We used "Adolescent Psychological Toughness Scale" compiled by $\mathrm{Hu}$ Yueqin and Gan Yiqun [10] as the psychological resilience scale.The scale was five-level scored and had 27 topics which included five factors such as family support, interpersonal assistance, goal focus, positive awareness, and emotion control. The alpha coefficient of the scale was 0.85 . Students who got scores below 3 points are of low psychological elasticity, 3 points to 4 points are of moderate psychological elasticity, 4 points or more are of high psychological elasticity. The level of psychological elasticity is determined by the scores. The higher the score is, the better the psychological elasticity is.

\section{RESULT AND ANALYSIS}

The statistical data of this research is obtained by importing the valid data into SPSS 17.0 software and then analyzing the surveyed results after excluding the invalid questionnaires.

\section{A. General Overview of the Coping Styles of Higher Vocational Students' Employment Pressure}

TABLE I. Descriptive Statistics on the Coping StYles of Higher Vocational Students’ EmPloyment Pressure

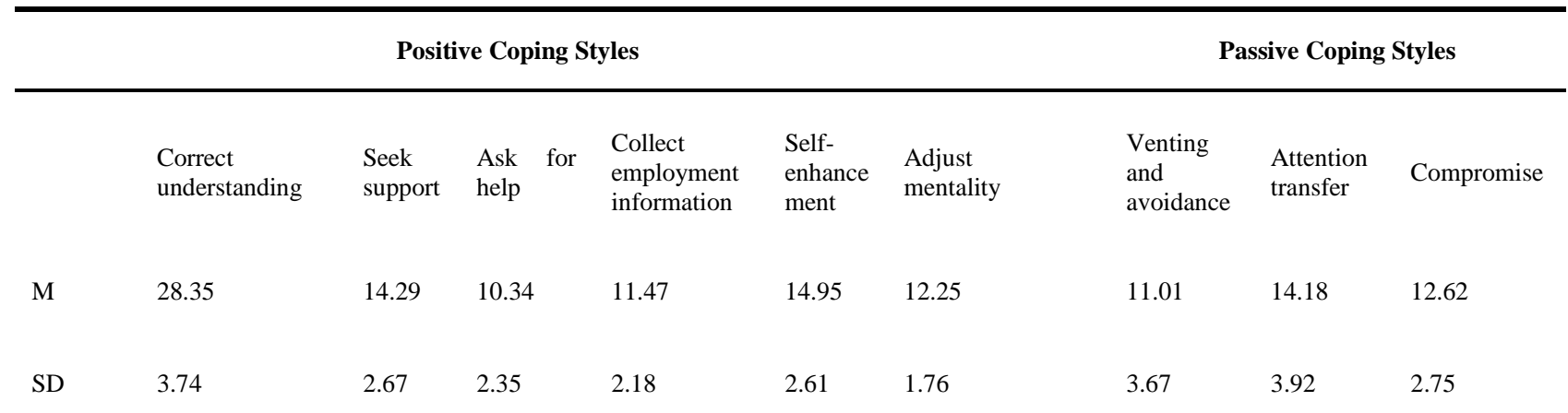

From the data in "Table I", it can be seen that in all dimensions of coping styles of higher vocational students' employment pressure, the maximum average value is the correct understanding, and the minimum is asking for help, and the second is self-enhancement. Therefore, generally speaking, when the higher vocational students are faced with employment pressure, the most widely used method is correct understanding and self-enhancement, and asking for help is least used. Calculated from the data in the table, the overall average score of positive coping style and passive 
coping style of employment pressure is 15.28 and 12.60 respectively, which can be concluded that the higher vocational students are more likely to take a positive coping style. In coping with the dilemma of employment pressure, the higher vocational students mainly adopt the positive coping styles, and the strategies adopted frequently are correct understanding, self-enhancement and seeking support. The positive coping styles adopted are mainly attention transfer and compromise.

\section{B. General Overview of Higher Vocational Students' Psychological Resilience Status Quo}

TABLE II. DESCRIPTIVE STATISTICS FOR HIGHER VOCATIONAL STUDENTS’ PSYCHOLOGICAL RESILIENCE

\begin{tabular}{llllll}
\hline & $\begin{array}{l}\text { Target } \\
\text { focus }\end{array}$ & $\begin{array}{l}\text { Interpersonal } \\
\text { assistance }\end{array}$ & $\begin{array}{l}\text { Positive } \\
\text { cognition }\end{array}$ & $\begin{array}{l}\text { Family } \\
\text { support }\end{array}$ & $\begin{array}{l}\text { Emotional } \\
\text { control }\end{array}$ \\
\hline $\mathrm{M}$ & 3.71 & 3.50 & 3.99 & 3.61 & 3.00 \\
$\mathrm{SD}$ & 0.59 & 0.72 & 0.62 & 0.46 & 0.67 \\
\hline
\end{tabular}

"Table II" shows that the higher vocational students score better in all dimensions. The highest is positive cognition, followed by target focus, family support and interpersonal assistance, and the lowest is emotional control.
Further taking coping style of employment pressure as dependent variable, and three factors of gender, grade and specialty division as independent variable, we will carry out the one-way analysis of variance and independent-sample $t$ test on the data to study the differences of the higher vocational students' employment pressure coping style on the three factors. From the data, it can be concluded that there is marginal gender significance in positive coping style, and the coping style of boys are slightly more positive than those of girls. There are no obvious differences in the coping style of employment pressure of higher vocational students in grade and speciality.

Taking psychological resilience as dependent variable, and three factors of gender, grade and specialty division as independent variable, we will carry out the one-way analysis of variance and independent-sample $t$ test on the data to study the differences of the higher vocational students' psychological resilience on the three factors. It can be drawn from the data that there are no obvious differences in the psychological resilience of higher vocational students in gender, grade and speciality.

\section{Relationship between Psychological Resilience and Employment Pressure Coping Style of Higher Vocational Students}

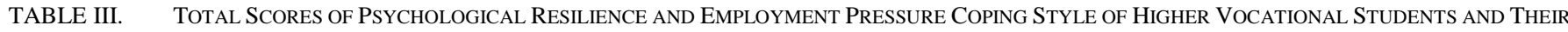
CORRELATION COEFFICIENTS ON ALL DIMENSIONS

\begin{tabular}{|c|c|c|c|c|c|c|}
\hline & B & B1 & B2 & B3 & B4 & B5 \\
\hline $\mathrm{C}$ & $0.233 * *$ & & & & & \\
\hline $\mathrm{C} 1$ & $0.468 * *$ & $0.510 * *$ & $0.258 * *$ & $0.248^{* *} *$ & $0.170^{* *}$ & $0.321 * *$ \\
\hline $\mathrm{C} 2$ & $-0.379 * *$ & $-0.315^{* *}$ & $-0.132 * *$ & $-0.178 * *$ & $-0.193 * *$ & $-0.391 * *$ \\
\hline $\mathrm{C} 3$ & $0.417 * *$ & $0.373 * *$ & $0.039 * *$ & $0.290^{* *}$ & $0.191^{* *}$ & $0.190^{* * *}$ \\
\hline $\mathrm{C} 4$ & $0.294 * *$ & $0.344 * *$ & $0.164 * *$ & $0.173 * *$ & $0.172 * *$ & $0.127 * *$ \\
\hline $\mathrm{C} 5$ & $-0.327^{* *}$ & $-0.308^{* *} *$ & -0.174 & -0.027 & $-0.205^{* *}$ & $-0.298 * *$ \\
\hline C6 & $0.260 * *$ & $0.348^{* *}$ & $0.062 * *$ & $0.227 * *$ & $0.118^{*}$ & $0.145^{* *}$ \\
\hline $\mathrm{C} 7$ & $0.305^{* *}$ & $0.383 * *$ & $0.134 * *$ & $0.248 * *$ & $0.104 *$ & $0.160^{* * *}$ \\
\hline $\mathrm{C} 8$ & $-0.133 * *$ & $-0.165^{* *}$ & $-0.146^{* *}$ & -0.050 & -0.002 & -0.046 \\
\hline $\mathrm{C} 9$ & $0.402 * *$ & $0.340 * *$ & $0.144 * *$ & $0.262 * *$ & $0.135^{* *}$ & $0.408^{* *} *$ \\
\hline
\end{tabular}

a. Note: * indicates that it is significant at the level of 0.05 , and ** indicates that it is significant at the level of 0.01 . "B"= psychological resilience, "C" = employment pressure coping style, "B1"= target focus, "B2"= international assistance, "B3"= positive cognition, "B4"= family support (dimension of psychological resilience), "B5"= emotional control, "C1"= correct understanding, "C 2 "= venting and avoidance, "C 3 " =

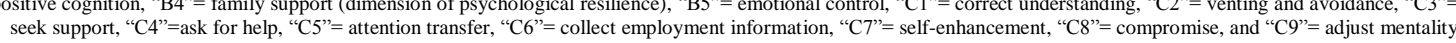

The coping style of employment pressure, psychological resilience and its various dimensions are analyzed. The research data in Table III indicates that the correlation between psychological resilience and employment pressure coping style has reached a significant level in general. The $\mathrm{p}$ value of psychological resilience and employment pressure coping style is less than 0.01 , which shows that there is a very significant positive correlation between the two, and the correlation coefficient is 0.233 . Psychological resilience is very negatively correlated with attention transfer, venting and avoidance and compromise. The positive relationship between psychological resilience and correct understanding, seeking support, asking for help, employment information collection, self-enhancement and adjustment of mentality is particularly significant. Therefore, it can be concluded that the higher the score of psychological resilience is, the more they cope with it positively, and on the contrary, it will be easier for them to take.

The reason why psychological resilience plays a role in the coping styles of employment pressure is mainly due to the effect of internal and external protective factors of 
psychological resilience. The internal protective factors refer to trait, personality, ability and so on, which are the embodiment of individual force in the mental resilience. External protective factors refer to family, society and so on, which are embodiment of supportiveness in the mental resilience. The protective factors affect the individual's psychological resilience through internal protective factors. The enhancement of psychological resilience will cause a positive coping style of employment pressure.

\section{COUNTERMEASURE AND SUGGESTION}

From the research results, it can be found that the positive coping style of employment pressure of students can be greatly enhanced by improving higher vocational students' psychological resilience. The improvement of psychological resilience can be started from the following three aspects:

1) Target focus: The strong or weak willpower depends on whether they concentrate on the target. In the ordinary life and learning, we should begin to create opportunities for cultivating our willpower, actively set goals for ourselves, and do not give up easily in the process of achieving goals, so as to form a psychological quality of being more brave than before. Making the higher vocational students realizes that they shall face the setbacks bravely since the setbacks are unavoidable in life. Therefore, when they are repeatedly rejected in their job search, they will not feel helpless or shrink back. Their positive psychological qualities and spirit of never accepting failure can become their powerful backing.

1) International communication: The research results show a certain degree of social support has a very significant impact on the improvement of the psychological resilience of higher vocational students. Major universities and families should become the supporters and guides for relieving the pressure of higher vocational students, actively pay attention to their psychological states, and give them the greatest support, making them perceive that they have a good interpersonal support system, are not alone, and can always find someone to support and care for themselves. Taking this opportunity, we can strengthen their psychological antipressure ability and improve the level of psychological resilience.

3)Positive cognition: Family and school education should guide vocational college students to establish a correct employment concept and change the wrong concept (only care for the pursuit of institutions, brand-name enterprises, high salary and high position, stability, one-shot employment on the lifetime, etc.), assist vocational college students to establish a scientific understanding of employment and make their career planning, and choose the field where his advantages line in and love the job that he has chosen.

We believe that through the above efforts, higher vocational students' psychological resilience can be further enhanced, and then further enable them to adopt more positive employment pressure coping styles.

\section{REFERENCES}

[1] Li Limin. Study on the Relationship between Employment Pressure Bearing Capacity and Social Support of Graduating Students in Chongqing[J]. 2010, 4

[2] Zhang Bing. Relationship between Personality Factors, Subjective Stress and Coping Style of Judicatory Constable Institute Students[J] Northeast Normal University, 2006.

[3] Canas, J.J, Quesada, J.F; Antoli, A;Fajardo. I cognitive Flexibility and adaptability to environmental changes in dynamic complex problem-solving tasks 2003 [15]Arianne D.Stevens Social ProblemSolving and Cognitive Flexibility :Relations to Social Skills and Problem Behavior of At-Risk Young Children .A dissertation submitted in partial fulfillment Of the requirements for the degree of Doctor of Philosophy In Clinical Psychology , 2009.

[4] Tan Lingling, He Lingling. The Coping Styles of Nursing Work and the Influence of Demographic Variables on It[J].2010, (8).

[5] Guo Nan. Review on College Graduates' Psychological Pressure and Coping Styles[J]. Medical Education Website,2006,4(5):384-385.

[6] Yu Xiaonan, Zhang Jianxin. Resilience - The Psychological Mechanism for Recovery and Growth under Pressure[J]. Advances in Psychological Science.2005,13(5)

[7] Sun Jihong. The Relationship between Psychological Resilience, Social Support and Coping Style of Military College Students[J].2013(1)

[8] Wan Yuchen, Yang Hai, Miao Danmin. The Relationship between Psychological Resilience, Social Support and Coping Style of Military College Students[J]. Journal of Shanxi Medical University. 2010,41(11)

[9] Luo Xili. The Compilation and Measurement of the Coping Style Questionnaire for College Students' Employment Pressure[D]. College of Economics and Management of Southwest University, 2008.

[10] Hu Yueqin, Gan Yiqun. Development and Psychometric Validity of the Resilience Scale for Chinese Adolescents[J]. Acta Psychologica Sinica 2008,40(8): 902 912 